\title{
Special Emphasis on Seismic Resistant Design of Non-seismically Designed Buildings in Hong Kong
}

\author{
Eddie Siu-Shu Lam ${ }^{1}$, Zhi-Dong Yang1, Vivian Wong ${ }^{1}$, Bo Li \\ ${ }^{1}$ The Hong Kong Polytechnic University \\ Hung Hom, Hong Kong, China \\ siu.shu.eddie.lam@polyu.edu.hk \\ ${ }^{2}$ The University of Nottingham \\ Ningbo, Zhejiang Province, China
}

\begin{abstract}
Buildings in Hong Kong were and still are traditionally designed without seismic provisions. Researches on seismic effects of buildings in Hong Kong have been carried out. Seismic performance of existing buildings and structural members has been examined theoretically and experimentally. This has exposed various deficiencies in the resistance of existing buildings against moderate seismic action. This paper aims to highlight some of the relevant researches carried out at The Hong Kong Polytechnic University and by the local researchers. Special emphasis is on the unique characteristics of buildings in Hong Kong including, inter alia, geological profile leading to the soil amplification effect, transfer structures, vulnerability of low-rise buildings, no separation between adjacent buildings, enclosed balconies with additional loading and poor detailing of structural members. Strengthening strategies for structural members are recommended including confinement of columns by high performance ferrocement and strengthening of beam-column joints by ferrocement jackets and diagonal reinforcements or by ferrocement jackets with chamfers. Practical approaches to mitigate the seismic risk are suggested including the use of dampers and structural control devices. Fluid dampers are also proposed to link adjacent buildings for seismic mitigation.
\end{abstract}

Keywords: Buildings, Seismic, Non-seismically-designed, Detailing, Retrofit

\section{Introduction}

After the sovereignty in 1997, seismic hazard of Hong Kong has been subjected to Chinese Code for Seismic Design of Buildings [1]. Studies by Pun and Ambrasseys [2], Lung et al. [3] and Wong et al. [4] have consistently demonstrated that Hong Kong is an area with moderate seismic risk. According to Pappin et al. [5] and Koo et al. [6], geological profile of Hong Kong is very complex with considerable fluctuation of soil depth above the rock face. Most of the land in Hong Kong is comprised of igneous rocks, sedimentary rocks and superficial deposits like alluvium. Near the Victoria Harbour, there are large areas of reclamation and this induces the soil amplification effect (e.g. Wong et al. [4]). With reference to "Seismic Ground Motion Parameter Zonation Map of China" [7], recommended peak ground acceleration of Hong Kong with a return period of 475 years is $0.15 \mathrm{~g}$ on rock site. As a major financial center and one of the densely populated cities, interruption to critical facilities and business operations in Hong Kong may cause serious social and economic consequences. Thus, the government is going to implement a seismic resistant design for buildings in Hong Kong in the foreseeable future. This paper aims to highlight some of the relevant researches carried out at The Hong Kong Polytechnic University and by the local researchers.

\section{Buildings in Hong Kong}

Most of the buildings in Hong Kong are reinforced concrete structures. A small class of tenement buildings built in late $19^{\text {th }}$ century to the 1960 s, the so-called "Tong Lau", are 2- to 5-story reinforced concrete frames with infill brickworks. Another small class of buildings are 10- to 12-story that were once subjected to the height limit of the old Kai Tak Airport. In the New Territories, there are village houses built by indigenous villagers, the so-called New Territories exempted houses. These are 3-storey small houses with a height limit of $8.23 \mathrm{~m}$ and with a roofed-over area not exceeding $65.03 \mathrm{~m}^{2}$. 
Save and except the above, majority of the buildings constructed after the 1980s are high-rise buildings with over 30-story in the city centres and around 10-story in the countryside.

Typical structural systems of high-rise buildings comprise coupled shear walls, transfer system at lower story and asymmetrical on plan. As demonstrated by Scot et al. [8], low rise buildings and transfer structures are vulnerable to seismic loading. Li et al. [9] performed shaking table tests on a 1/20-scale high-rise building model. As shown in Fig. 1, the model represents a reinforced concrete building with 34 typical floors supported by a $2.7 \mathrm{~m}$ thick transfer plate sitting over a 3-level podium. Based on the test results and numerical analysis, the high-rise building may survive the strong earthquake action possibly experienced in Hong Kong. This is through the coupling effect introduced by the transfer plate.

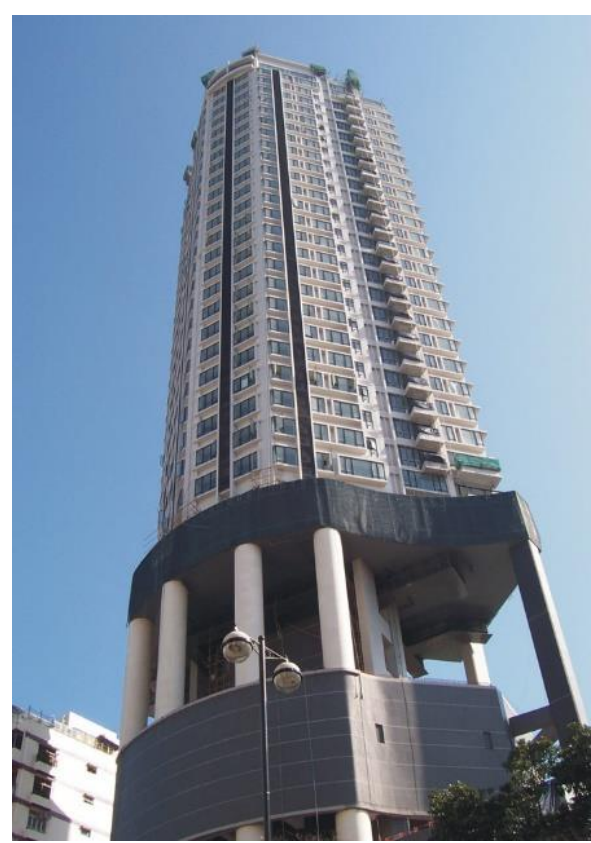

(a) Building with a transfer plate

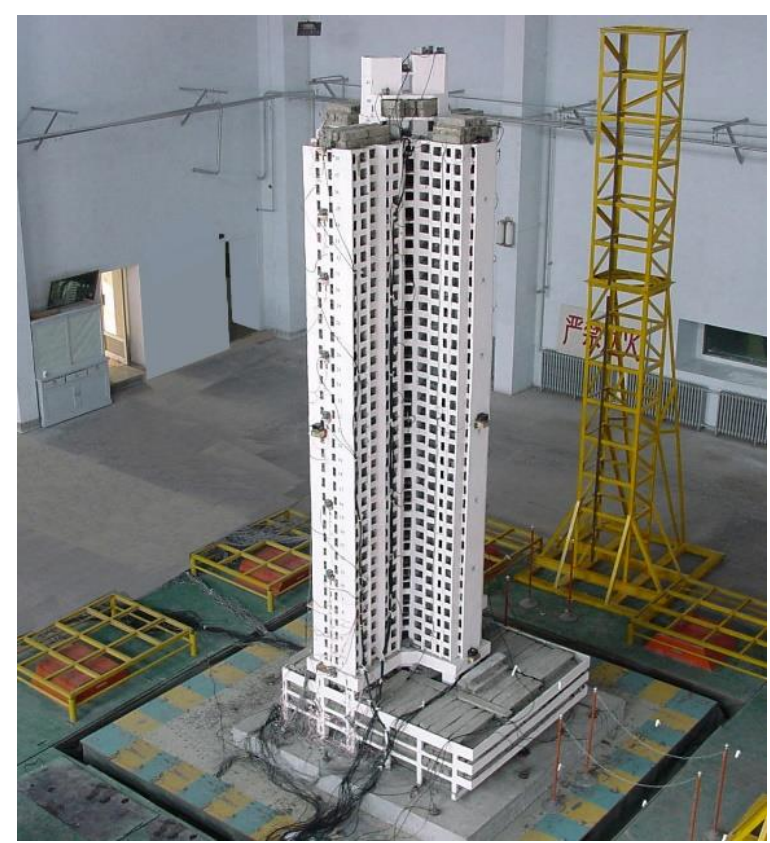

(b) The $1 / 20$-scale model on a shaking table

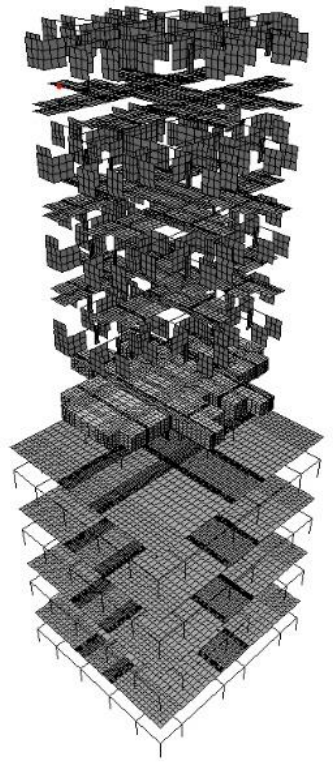

(c) Finite element representation

Fig. 1: Experimental and numerical studies of a $1 / 20$-scale high-rise building with a transfer plate.

Dai et al. [10] examined the torsional effect of a 1/6-scale 9-story asymmetrical reinforced concrete frame. The model was tested on a shaking table under different levels of earthquake attack. It has been shown that the destructive effect caused by torsion escalates when the frame is damaged.

According to $\mathrm{Su}$ et al. [11], buildings exceeding $45 \mathrm{~m}$ in height, having a soft-storey and located in a deep soft soil site are potentially vulnerable to earthquake attack. Leung et al. [12] studied the structural performance of seven existing buildings by applying linear modal superposition method and time history analysis. Analysis results have indicated that low-rise buildings may suffer substantial from damage and collapse under strong earthquake. 

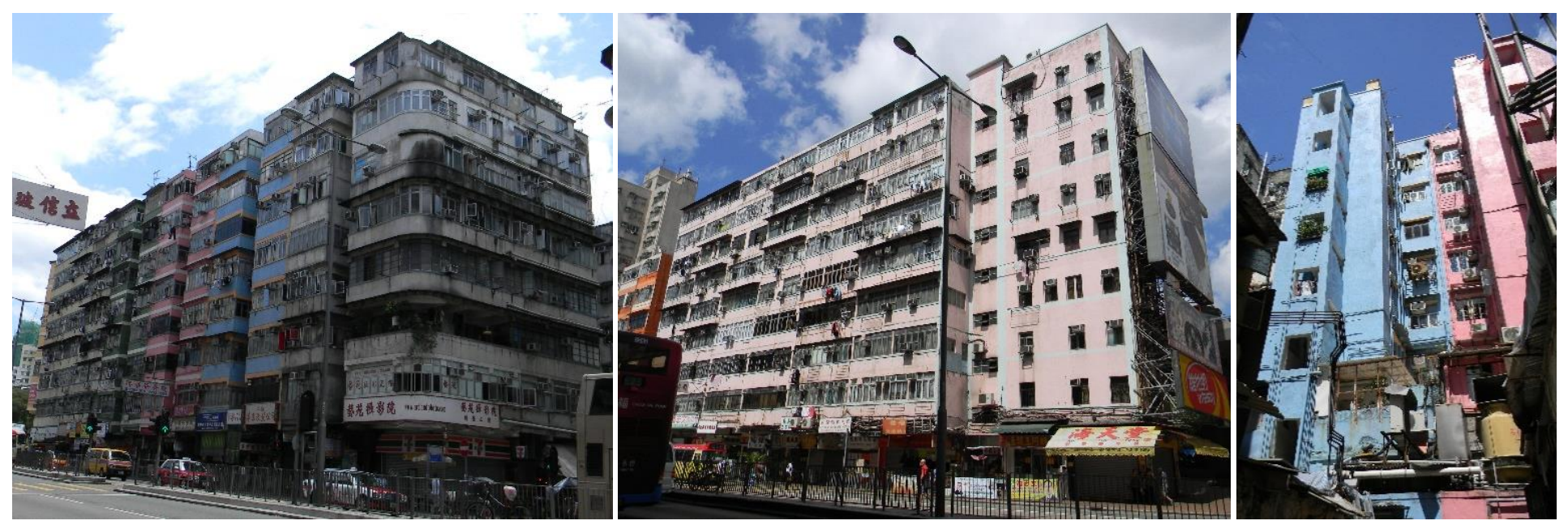

Fig. 2: No separation between the buildings in old districts (e.g. in Kowloon).

There is no separation between the adjacent buildings completed before the 1980s. Examples are given in Fig. 2 from the old districts in Kowloon. As demonstrated by Chau and Wei [13], pounding between adjacent buildings would take place posing serious seismic hazard.

Balconies are common features in our residential buildings. These are cantilevered structures projecting from the building envelops. In the old districts as shown in Fig. 2, balconies are enclosed. These are illegal/unauthorized works that alter the use of balconies from an open area to an enclosed living area. Apart from an increase in loading not anticipated in the design, cantilevered structures are structural form not desirable for seismic resistance.

\section{Structural members}

In the subtropical region, Hong Kong is constantly attacked by typhoons. To resist the wind load, shear walls and core walls are adopted in high-rise buildings as the principal lateral load resisting elements. There is no boundary elements at the ends of shear walls. When subjected to cyclic actions induced by an earthquake, ends of shear walls may fail as they are unprotected and without proper confinement.

In the absence of seismic resistant design, coupling beams, commonly used to link up the shear walls, are without seismic detailing and with no provisions for plastic hinge zones. Liu et al. [14] and Pam et al. [15] conducted cyclic loading tests on non-seismically designed coupling beams at different shear span ratios. The studies have indicated that displacement ductility of coupling beams is generally between 3 and 6 . To improve the displacement ductility, it is recommended to increase the number of legs, reduce the spacing of transverse reinforcements and embed steel plates with shear studs.

Beams are heavily reinforced. There is no provisions for plastic hinge zones and main reinforcements can be discontinuous between spans.

In the absence of seismic resistant design, reinforced concrete columns are subjected to high axial load. To facilitate the building plans, square/rectangular columns are applied to typical floors whereas circular columns are commonly assigned to podium structures. They are heavily reinforced with typically $4 \%$ main reinforcements. As demonstrated by, e.g. Lam et al. [16] and Kuang and Wong [17], the deficiencies include poor transverse reinforcement detailing with 90degree hooks and insufficient confinement [16]. It has also been shown that the dependable displacement ductility of this class of columns is highly inadequate.

Since the introduction of Code of Practice of for Structural Use of Concrete 2004 [18] to Hong Kong, beam-column joints are required to be provided with horizontal and vertical shear reinforcements. As such provisions are not in the pre2004 concrete code, beam-column joints designed to pre-2004 concrete code have insufficient shear resistance and insufficient confinement in the joint cores. Pam et al. [15] and Li et al. [19] conducted reverse cyclic loading tests on beam-column joints without seismic detailing. The test results showed shear failure at the joints with inadequate ductility. Further, Li et al. [20] have also demonstrated the adverse effect to beam-column joints arising from the high axial load acting on the columns. 


\section{Strengtheing of reinforced concrete memebers by ferrocement}

Among others, Chan et al. [21, 22], Pam et al. [15], Lam et al. [16], Su et al. [23] and Leung et al. [12] have consistently indicated seismic deficiency in the existing buildings and a need to strengthen the existing buildings for proper seismic resistance.

Teng et al. [24] presented various methods to retrofit columns using FRP. This includes the use of FRP jackets with horizontally oriented fibers and a combination of longitudinally bonded and laterally bonded FRP.

To strengthen non-seismically designed columns, high performance ferrocement ("HPF") has been proposed to provide adequate confinement action [25]. HPF is a type of ferrocement with improved strength-to-weight ratio and increased tensile strength. As illustrated in Fig. 3, application of HPF comprises three consecutive steps: (a) proper preparation of surface, (b) installation of wire meshes and (c) application of rendering material.

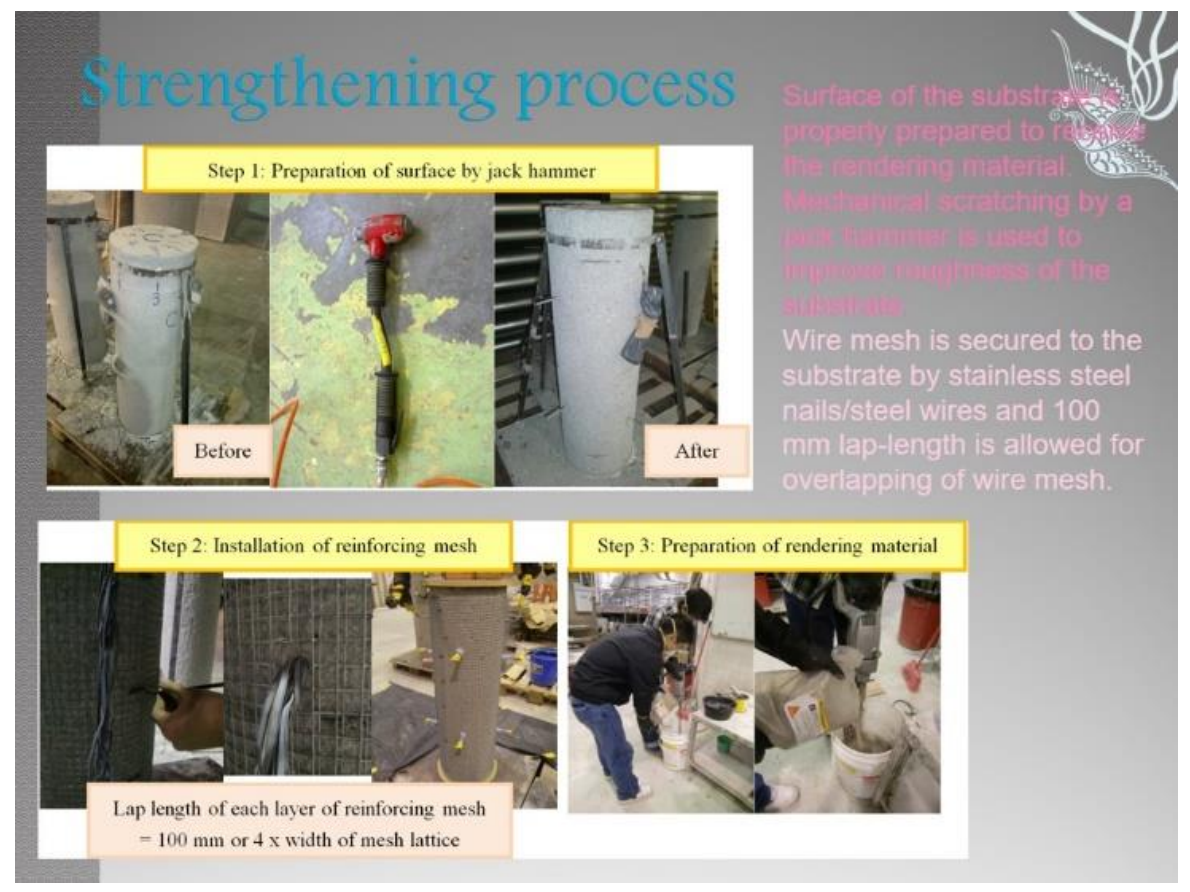

Fig. 3: Strengthening of columns by HPF.

Beam-column joint is a key member that affects the overall behaviour of buildings under seismic action. As demonstrated by Pampanin et al. [26], beam-column joints without transverse reinforcement in the joint cores (i.e. designed to gravity action only, similar to those commonly found in Hong Kong) exhibit poor seismic performance. In recognizing the need to satisfy fire rating and to minimize increase in member size, concrete jacketing has been revisited. Li et al. [19] have successfully developed a method of strengthening beam-column joint using ferrocement jackets and diagonal reinforcements. As shown in Fig. 4, ferrocement is used to replace the concrete cover in the joint region. Rendering material with welded square mesh is applied as ferrocement. Two diagonal reinforcements are installed in the joints and anchored to the main reinforcements of the beams to reduce the force transferred to the joints. 


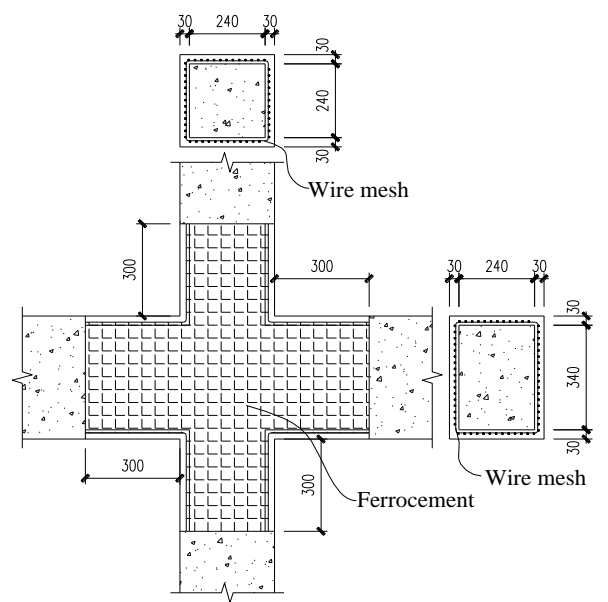

(a) Ferrocement wrapping

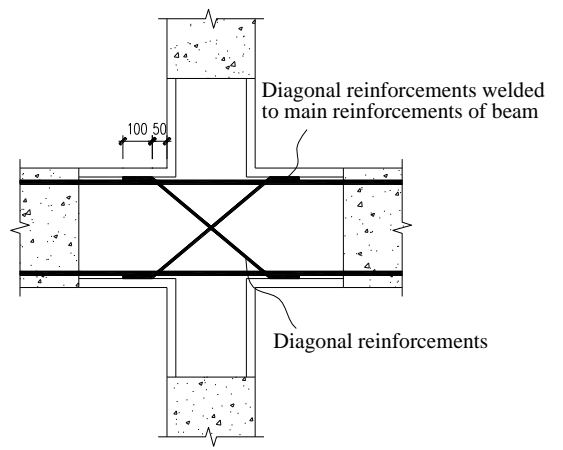

(b) Diagonal reinforcements

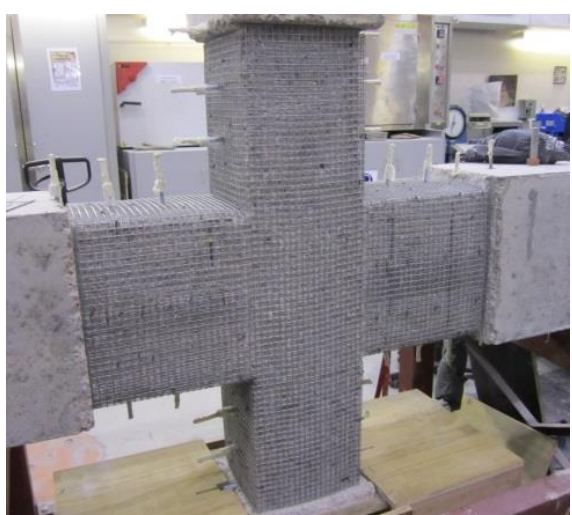

(c) Wire mesh installed

Fig. 4: Strengthening scheme for interior beam-column joint.

Recently, Li et al. [27] have successfully applied (triangular) chamfers to strengthen exterior beam-column joints. Based on the test results, shear failure was suppressed and chamfers could be provided without skeleton reinforcement. See Fig. 5(a): chamfers without skeleton reinforcement (top left) and with skeleton reinforcement (top right). Further, external beam-column joints with one chamfer exhibit only a slight decrease in peak strength and energy dissipation. Thus, strengthening using one chamfer is a viable method, e.g. under the soffit of a beam as shown in Fig. 5(c), to minimize the impact to the use of space.

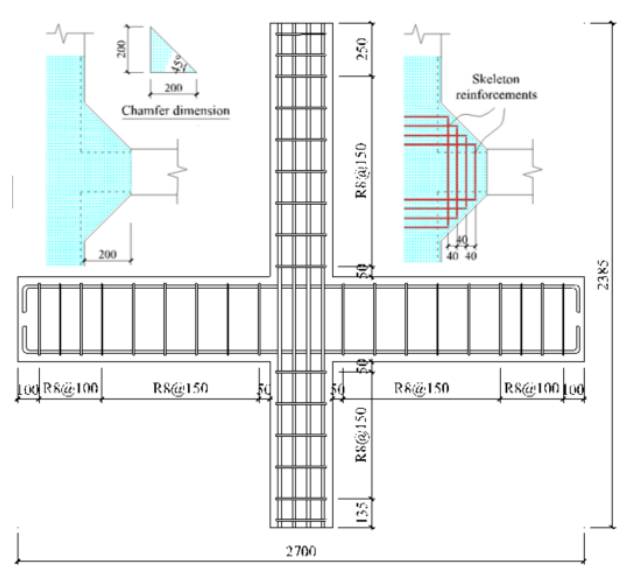

(a) Specimen and chamfers

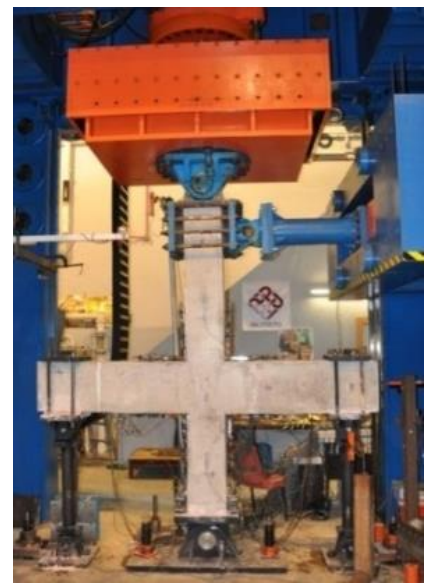

(b) Test set up

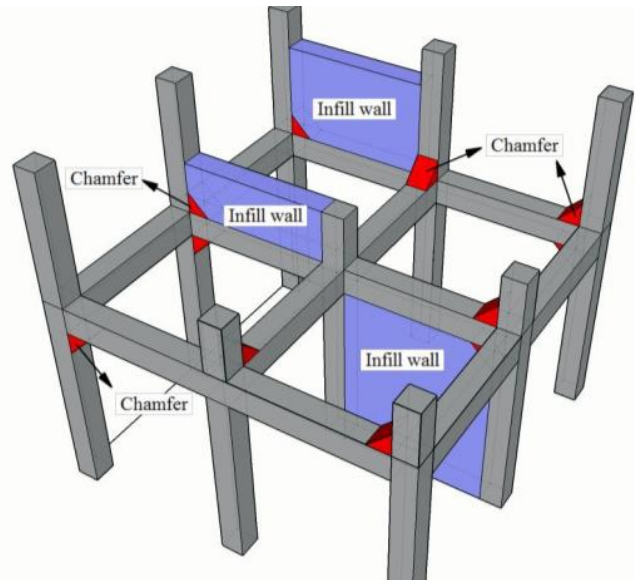

(c) Examples of chamfers

Fig. 5: Exterior beam-column joints with chamfers.

\section{Strengtheing of buildings by structural control devices and dampers}

In Hong Kong, significant progress in structural control has been developed in the past years to retrofit existing structures and to enhance the performance of new structures against earthquakes. Shi and Zhu [28] have developed two novel magnetic negative stiffness dampers. As shown in Fig. 6, the dampers comprise several permanent magnets in a conductive pipe to provide negative stiffness and damping. Qiu and Zhu [29] proposed the use of self-centering braces to reduce the response of frame structures at higher modes of vibration.

Seismic performance of reinforced concrete structures can be significantly improved by increasing the energy dissipation capacity through the use of energy dissipation devices. To enhance the response of dampers under moderate seismic action, Chung and Lam [30] developed a displacement amplification system to amplify the displacement through a hydraulic system. As shown in Fig. 7, performance of the hydraulic displacement amplification system was experimentally verified by a $1 / 3$-scale prototype. 


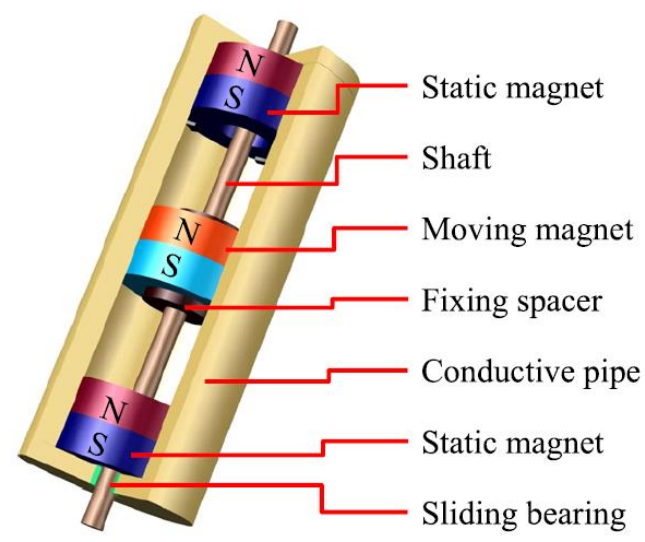

Fig. 6: Magnetic negative stiffness damper.
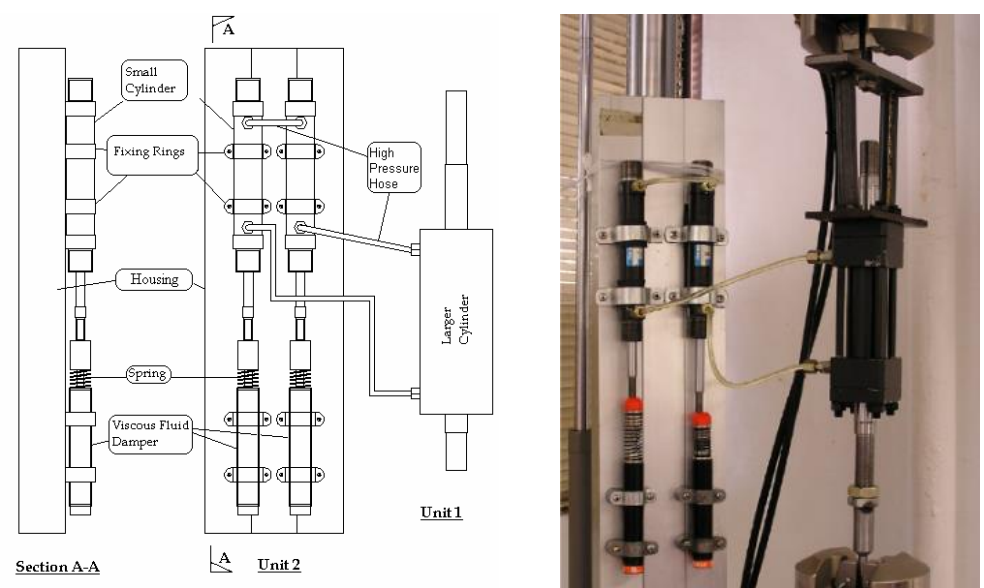

Fig. 7: Hydraulic amplification system.

\section{Strengtheing of adjacent buildings by coupling method}

As land is limited in Hong Kong, adjacent buildings are planned to be very close to each other. For those completed before the 1980s, there is no separation between the buildings (i.e. no seismic joints). To minimize the effect of pounding and to improve the seismic performance between adjacent buildings, Zhu et al. [31, 32], Zhang and $\mathrm{Xu}$ [33] and $\mathrm{Xu}$ et al. [34] proposed to connect adjacent buildings by dampers for seismic mitigation. Parametric studies were conducted to evaluate the reduction of seismic response. By increasing the modal damping ratios, fluid dampers can mitigate seismic response of the coupled buildings. Through theoretical and experimental studies, it has be demonstrated that fluid dampers can effectively mitigate the response to sinusoidal excitation. 


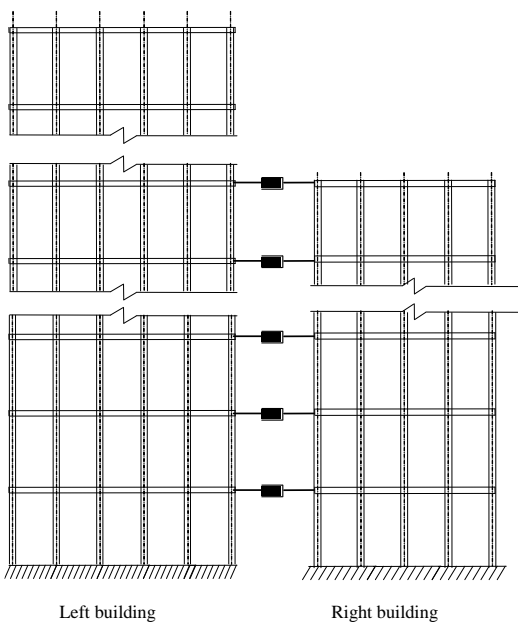

(a) Adjacent buildings

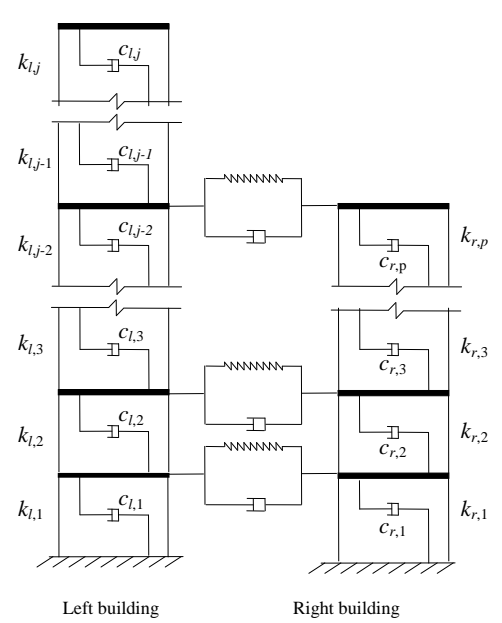

(b) Analytical models

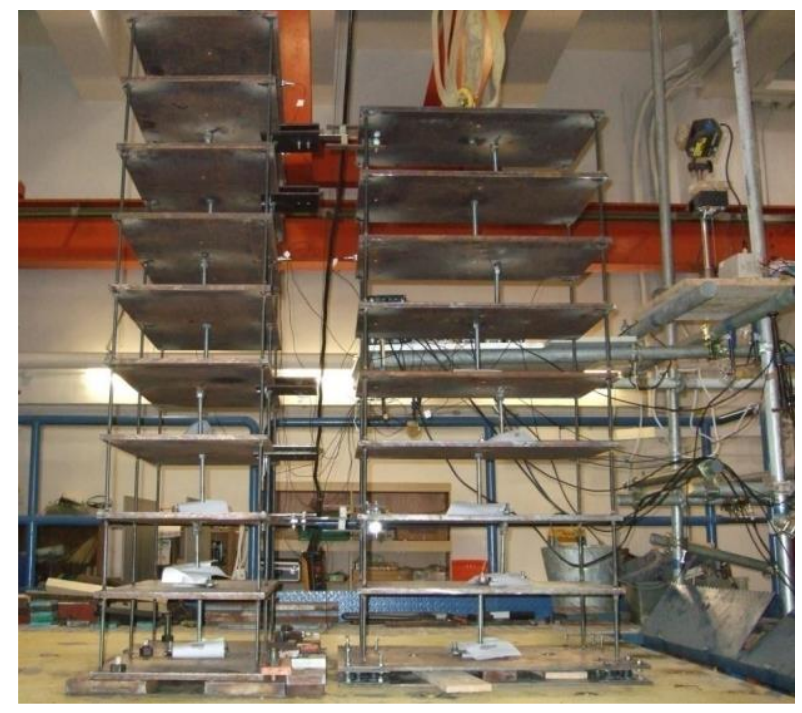

(c) Shaking table test

Fig. 8: Coupling adjacent buildings by dampers.

As shown in Fig. 8, Yang [35] proposed to connect two shear type buildings with different number of stories by fluid dampers. Mathematical models were developed to optimize both locations and properties of damper at the frequency domain. Pursuant to Chinese Code for Seismic Design of Buildings [1], time-history analyses were conducted on selected earthquake records. Shaking table tests were performed on two steel frames connected by dampers at different floor levels. It has been shown that seismic response of two buildings having different number of stories can be significantly controlled by coupling the response by fluid dampers.

\section{Conclusions}

It is now well recognised that Hong Kong is a region with moderate seismic risk. Geological profile of Hong Kong is very complex with considerable fluctuation of soil depth above the rock face and large area of reclamation. This induces soil amplification effect. Peak ground acceleration of Hong Kong with a return period of 475 years is $0.15 \mathrm{~g}$ on rock site. As buildings in Hong Kong have been designed with no seismic provisions, it is necessary to consider the seismic performance of existing buildings and structural members to recommend proper strengthening strategies.

Unique characteristics of our buildings are as follows.

1.High-rise buildings have transfer structures at lower story and asymmetrical on plan.

2.Low-rise buildings may suffer from substantial damage and collapse under strong earthquake.

3.There is no separation between adjacent buildings and pounding will take place posing serious seismic hazard.

4.Enclosed balconies may have insufficient seismic resistance.

Studies have exposed various deficiencies in the resistance of local buildings against moderate seismic action. In particular, structural members including coupling beams, beams, beam-column joints, columns and walls are in lack of proper detailing for seismic resistance.

Seismic performance of buildings designed without seismic consideration has been examined theoretically and experimentally. Strengthening strategies for structural members include the following.

1.Columns can be strengthened by replacing the concrete cover with high performance ferrocement.

2.Beam-column joints can be strengthened by applying ferrocement jackets and diagonal reinforcements to reduce the force transferred to the joint cores or by ferrocement jackets with chamfers to enlarge the effective joint area and relocate the plastic hinges.

Practical approaches to mitigate the seismic risk are recommended. Structural control devices can be applied to strengthen existing buildings and enhance the performance of new structures against earthquakes. Fluid dampers are proposed to link adjacent buildings for seismic mitigation. 


\section{Acknowledgements}

The authors are grateful to the financial supports from The Hong Kong Polytechnic University (Project No: 4-ZZCK). The authors would like to gratefully acknowledged Prof Y.L. Xu, Prof K.T. Chau, Prof Y. Xia and Prof S.Y. Zhu, The Hong Kong Polytechnic University, Prof R.K.L. Su, The University of Hong Kong and Prof J.S. Kuang, The University of Science and Technology.

\section{References}

[1] GB50011-2010, Code for Seismic Design of Buildings, Beijing: China Architecture \& Building Press, 2010.

[2] W. K. Pun and N. N. Ambraseys, "Earthquake data review and seismic hazard analysis for the Hong Kong region," Earthquake Engineering \& Structural Dynamic, vol. 21, no. 5, pp. 433-443, 1992.

[3] Y. L. Wong, J. X. Zhao, K. T. Chau and C. M. Lee, "Assessment of seismicity model for Hong Kong region," HKIE Transactions, vol. 5, no. 1, pp. 50-62, 1998.

[4] Y. L. Wong, J. X. Zhao, E. S. S. Lam and K. T. Chau, "Assessing seismic response of soft soil sites in Hong Kong using icrotremor records," HKIE Transactions, vol. 5, no. 3, pp. 70-79, 1998.

[5] J. W. Pappin, M. Free, J. Bird and R. Koo, "Evaluation of site effects in a moderate seismicity region, Hong Kong," in Proceedings of 13th World Conference on Earthquake Engineering, Vancouver, Canada, no. 1662, 2004.

[6] R. Koo, V. Kong and M. Free, "Seismic hazard assessment and site response evaluation in Hong Kong," in Proceedings of the SECED Young Engineers Conference, Bath, UK, 2005.

[7] GB18306-2001, Seismic Ground Motion Parameter Zonation Map of China, Beijing: China Architecture \& Building Press, 2001.

[8] D. M. Scott, J. W. Pappin and M. K. Y. Kwok, "Seismic design of buildings in Hong Kong," HKIE Transactions, vol. 1, no.2, pp. 37-50, 1994.

[9] C. S. Li, S. S. E. Lam, M. Z. Zhang and Y. L. Wong, "Shaking table test of a 1: 20 scale high-rise building with a transfer plate system," Journal of Structural Engineering, vol. 132, no. 11, pp. 1732-1744, 2006.

[10] J. W. Dai, Y. L. Wong and M. Z. Zhang, "Torsion response of reinforced concrete building under shaking table test," Advances In Structural Dynamics, vol. 2, pp. 859-865, 2000.

[11] R. K. L. Su, N. T. K. Lam and H. H, Tsang, "Seismic drift demand and capacity of non-seismically designed concrete buildings in Hong Kong," Electronic Journal of Structural Engineering, vol. 8, pp. 110-121, 2008.

[12] K. Leung, K. Tse, L. Lau, K. Lee, J. Lam, H. Zhang and X. Zhou, "Recent study on seismic evaluation of existing buildings - A Hong Kong perspective," HKIE Transactions, vol. 23, pp. 36-67, 2016.

[13] U. Ersoy, A. T. Tankut and R. Suleiman, "Behavior of jacketed columns," Structural Journal, vol. 90, no. 3, pp. 288-293, 1993.

[14] Z. Q. Liu, S. S. E. Lam and B. Wu, "Seismic performance of non-ductile coupling beams," in Proceedings of Structural Engineering World Congress (SEQC 2002), Japan, 2002.

[15] H. J. Pam, R. K. L. Su, W. Y. Lam, J. Li, F. T. K. Au, A. K. H. Kwan and P. K. K. Lee, "Designing coupling beams and joints in concrete buildings for improved earthquake resistance," in Proceedings of the Structural Symposium 2002, Recent Developments in Earthquake Engineering, Hong Kong, pp. 91-105, 2002.

[16] S. S. E. Lam, B. Wu, Y. L. Wong, Z. Y. Wang, Z. Q. Liu and C. S. Li, "Drift capacity of rectangular reinforced concrete columns with low lateral confinement and high-axial load," Journal of Structural Engineering, vol. 129, no. 6, pp. 733-742, 2003.

[17] J. S. Kuang and H. F. Wong, "Improving the seismic performance of reinforced concrete columns: A case-study of Hong Kong," HKIE Transactions, vol. 9, no. 3, pp. 20-25, 2002.

[18] Buildings Department, Code of Practice for Structural Use of Concrete 2004, Buildings Department, HKSAR Government.

[19] B. Li, S. S. E. Lam, B. Wu and Y. Y. Wang, "Experimental investigation on reinforced concrete interior beamcolumn joints rehabilitated by ferrocement jackets," Engineering Structures, vol. 56, pp 897-909, 2013.

[20] B. Li, S. S. E. Lam, B. Wu and Y. Y. Wang, "Effect of high axial load on seismic behavior of RC beam-column joints with and without strengthening," ACI Structural Journal, vol. 112, no. 6, pp. 713-723, 2015.

[21] H. C. Chan, A. D. E. Pan, H. J. Pam and A. K. H. Kwan, "Seismic detailing of reinforced concrete buildings with relevance to Hong Kong design practice (Part I)," HKIE Transactions, vol. 5, no. 1, pp. 6-13, 1998. 
[22] H. C. Chan, A. D. E. Pan, H. J. Pam and A. K. H. Kwan, "Seismic detailing of reinforced concrete buildings with relevance to Hong Kong design practice (Part II)," HKIE Transactions, vol. 5, no. 1, pp. 14-20, 1998.

[23] R. K. L. Su, T. O. Tang, C. L. Lee and H. H. Tsang, "Simplified seismic assessment of RC buildings in Hong Kong under occasional earthquake action," Innovation In Construction: Research Journal, vol. 2, pp. 45-54, 2015.

[24] J. G. Teng, J. F. Chen, S. T. Smith and L. Lam, FRP: Strengthened RC Structures. West Sussex, England: John Wiley \& Sons, 2002.

[25] I. F. Y. Ho, S. S. E. Lam, B. Wu and Y. Y. Wang, "Monotonic behavior of reinforced concrete columns confined with high-performance ferrocement," Journal of Structural Engineering, vol. 139, no. 4, pp. 574-583, 2013.

[26] S. Pampanin, G. M. Calvi and M. Moratti, "Seismic behavior of RC beam-column joints designed for gravity loads," in Proceedings of the $12^{\text {th }}$ European Conference on Earthquake Engineering, 2002, no. 726.

[27] B. Li, S. S. E. Lam, Y. K. Cheng, B. Wu and Y. Y. Wang, "Strengthening of non-seismically designed beam-column joints by ferrocement jackets with chamfers," Earthquakes and Structures, An International Journal, vol. 8, no. 5, pp. 1017-1038, 2015.

[28] X. Shi and S. Zhu, "Magnetic negative stiffness dampers," Smart Materials and Structures, vol. 24, no. 7, pp. $072002,2015$.

[29] C. X. Qiu and S. Zhu, "High-mode effects on seismic performance of multi-story self-centering braced steel frames," Journal of Constructional Steel Research, vol. 119, pp. 133-143, 2016.

[30] T. S. K. Chung and S. S. E. Lam, "Hydraulic displacement amplification system for energy dissipation," in Proceedings of 2004 ANCEER Annual Meeting, Honolulu, Hawaii, 2004.

[31] H. P. Zhu and Y. L. Xu, "Optimum parameters of Maxwell model-defined dampers used to link adjacent structures," Journal of Sound and Vibration, vol. 279, no. 1-2, pp. 253-274, 2005.

[32] H. P. Zhu, D. D. Ge and X. Huang, "Optimum connecting dampers to reduce the seismic responses of parallel structures," Journal of Sound and Vibration, vol. 330, no. 9, pp. 1931-1949, 2011.

[33] W. S. Zhang and Y. L. Xu, "Vibration analysis of two buildings linked by Maxwell model-defined fluid dampers," Journal of Sound and Vibration, vol. 233, no. 5, pp. 775-796, 2000.

[34] Y. L. Xu, S. Zhan, J. M. Ko and W. S. Zhang, "Experimental investigation of adjacent buildings connected by fluid damper," Earthquake Engineering \& Structural Dynamics, vol. 28, no. 6, pp. 609-631, 1999.

[35] Z. D. Yang, "Retrofitting existing buildings by coupling method using passive devices," Ph.D. dissertation, Department of Civil and Enviromental Engineering, The Hong Kong Polytechnic University, Hong Kong, 2015. 